\title{
Quantitative and Qualitative Assessment of the Structural Convergence of the Economy in the Transition to Sustainable Development
}

\author{
Sergey Zhironkin ${ }^{1,2^{*}}$, Olga Zhironkina ${ }^{3}$, Andrey Voloshin ${ }^{1}$, Julia Suslova ${ }^{1}$, and Roman \\ Shorokhov ${ }^{1}$ \\ ${ }^{1}$ Siberian Federal University, 660075 Lida Prushinskaya St. 2, Krasnoyarsk, Russia \\ ${ }^{2}$ T.F Gorbachev Kuzbass State Technical University, 650000, 28 Vesennya St., Kemerovo, Russia \\ ${ }^{3}$ Kemerovo State University, 650043, 6 Krasnaya St., Kemerovo, Russia
}

\begin{abstract}
At the present stage of the transition to sustainable development, when the share of a green economy in technologically advanced countries reaches one third of GDP, overcoming the structural crisis of the Russia is inseparable from reducing the technological gap and structural imbalances in the economy. These imbalances alienate Russia from ecologically and technologically advanced countries. Therefore, it is highly relevant to develop a methodology for assessing the structural convergence of the economy in the context of the transition to sustainable development, accompanied in developed countries by a new type of structural shift caused by the expansion of convergent technologies, the emergence of new principles of sectoral genesis and the formation of a green economy. The deepening of the divergent nature of Russian economy development was the result of a series of negative structural shifts that consolidated the dominance of extractive and resource-intensive industries, which threaten the final loss of technological identity, consolidation of the recessive trend and a lag in the transition to sustainable development. Therefore, today it is extremely important to formulate a methodology for assessing the structural convergence of Russian economy with technological and ecologically advanced countries, taking into account both quantitative and qualitative aspects.
\end{abstract}

\section{Introduction}

The need for a quantitative assessment of the convergent nature of structural shifts is increasing in the context of the transition to sustainable development associated with the search for adequate measures of convergent economic and environmental policy aimed at overcoming ecologically divergent trends in the development of Russia.

It is important to note that a quantitative analysis of the convergent nature of structural changes should not replace their qualitative analysis. This requires the development of indicators that reflect the entire system of complex transformations in the national economy

\footnotetext{
* Corresponding author: zhironkin@inbox.ru
} 
structure, such as an increase in investments in environmental protection measures, innovative activity, technological modernization of industry, and the expansion of international scientific and technical cooperation in the field of industrial ecology.

Equally important is the fact that indicators for assessing a convergent structural shift should be based on structural convergence and reveal the similarity of structural trends in the national economy as well as ecologically and technologically advanced countries. This should contribute to improving environmental and economic forecasting and timely identification of structural imbalances, determining the conditions and prospects for their implementation within the framework of sustainable development policy.

\section{Materials and Methods}

Approaches to quantitative assessment of structural dynamics is to calculate the indices of structural changes proposed by Russian and foreign researchers [1-5]. Analyzing approaches to the quantitative and qualitative assessment of convergent structural shifts, it was concluded that the method of aggregated assessment of structural convergence based on the aggregated index as an indicator that takes into account convergence of structural changes can be considered as relevant. We associate the importance of an aggregated analysis of structural convergence for understanding the problems of transition to sustainable development with an assessment of the correlation of the national economy with the most advanced standards of green industry, recycling and environmental protection, which are set by technologically leading countries [6-7].

It should be noted that modern science today has a certain set of integral indicators for assessing the consistency of economic and technological development, and environmental management used by rating agencies, international environmental organizations, and government authorities. Based on their advantages and disadvantages, disclosed in a number of studies [8-10], the requirements for quantitative indicators for assessing a convergent structural shift can be presented as follows:

- macroeconomic applicability, which means the ability of indicators to reflect the dynamics and accumulated changes in macro- and mesoeconomic proportions, as well as factors influencing them;

- verifiability and provability, what means calculation based on updated publicly known data from official statistics and relevant scientific research, applicable in a homogeneous economic environment;

- analyticity - the compliance with the terminological apparatus generally accepted in economic science, suitability for international comparisons and the development of models of macroeconomic regulation;

- consistency as a reflection of intrastructural interconnections, the factors of structural changes generated by them.

Taking into account these criteria, we proposed the following indicators to assess the convergent nature of the structural shift:

1. Aggregated index of convergent structural shift, with the help of which it is possible to assess the related nature of structural shifts in the national economy and in the economies of other countries and blocks (in relation to the purpose of the dissertation research - with technologically advanced countries and economic blocks with Russian residence, for example, BRICS).

2. Criteria indices of convergent structural shift - the main elements for calculating the aggregated index of convergent structural shift. They reflect the dynamics of certain criteria for structural convergence (Fig. 1). We supplemented the existing sets of convergence criteria with macrodynamic ones, since they directly characterize economic convergence 
(convergence of countries according to macro-indicators), and excluded institutional ones, since their quantitative calculation is difficult.

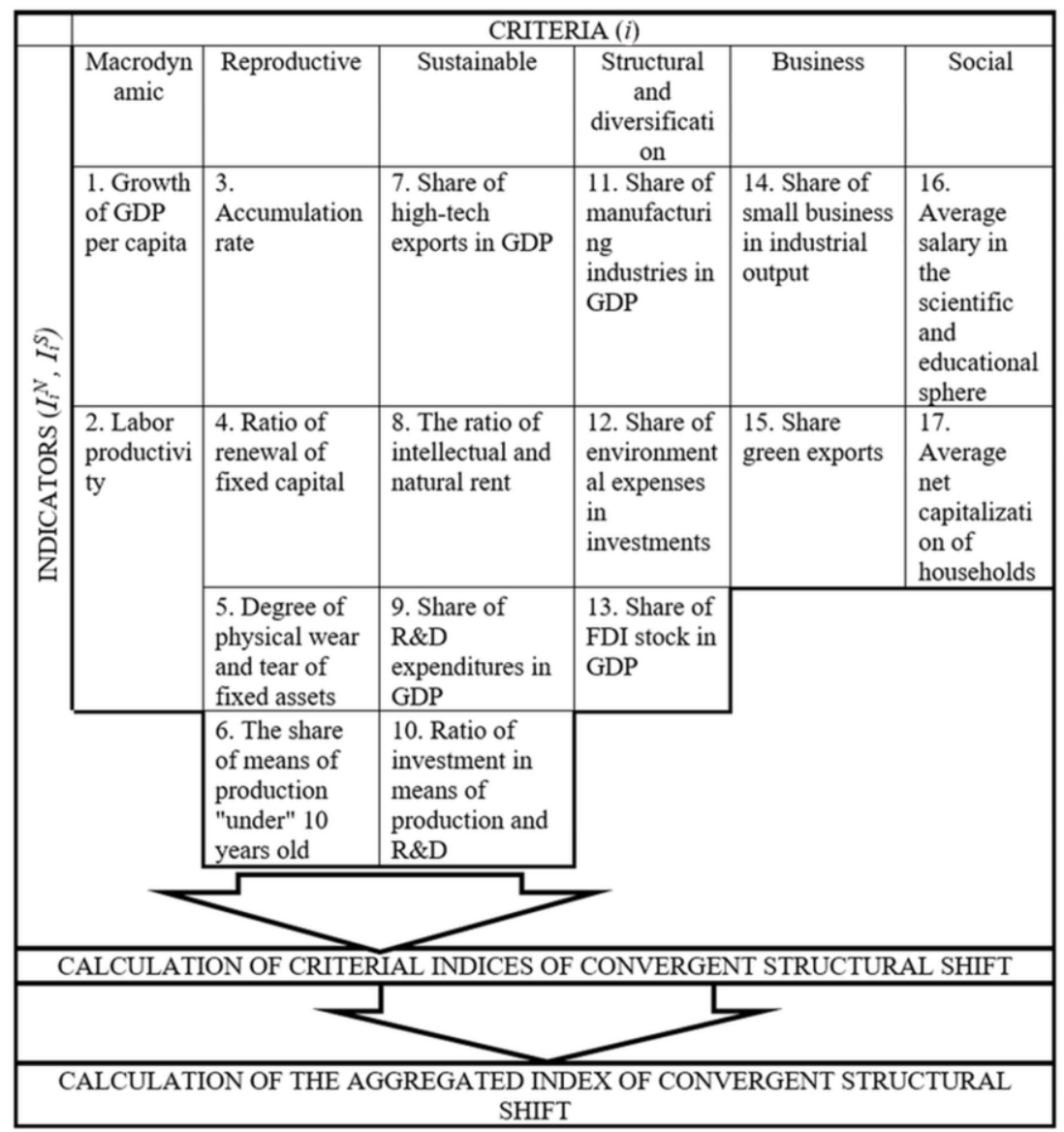

Fig. 1. Elements of the methodology for calculating the aggregated index of convergent structural shift.

The very methodology for calculating the aggregated index of convergent structural shift includes the following calculation sequence:

a) calculation of indicators of structural change within the framework of certain criteria for the national economy and the economy of a group of countries (1);

b) determination of criterion indices of a convergent structural shift (2);

c) calculation of the aggregated index of convergent structural shift (3).

To determine the structural shift index $\left(I-\right.$ in our method $I_{i}^{N}$ and $\left.I_{i}^{S}\right)$, we used the technique presented in the works of E.A. Taran [1-3]:

$$
I=D_{i} / D_{0}
$$

where: $D_{i}$ is the value of the structural indicator in the current period;

$D_{0}$ is the value of the structural indicator in the base period.

To calculate the criterion indices of the convergent structural shift, we use the formula (2): 


$$
\begin{aligned}
\operatorname{KICSS}_{i}^{N} & =\left(\prod_{i=1}^{m} I_{i}^{N}\right)^{1 / m} \\
\operatorname{KICSS}_{i}^{S} & =\left(\prod_{i=1}^{m} I_{i}^{S}\right)^{1 / m}
\end{aligned}
$$

where: $I_{i}^{N}$ is the structural shift index, calculated within the $i$-th criterion for the national economy for 1 year;

$I_{i}^{S}$ is the index of structural change, calculated within the $i$-th criterion for the compared group of countries for 1 year;

$\operatorname{KICSS}_{i}^{N}$ is the $i$-th criterion index of convergent structural shift, calculated for the national economy;

$\operatorname{KICSS}_{i}^{S}$ is I-th criterion index of convergent structural shift, calculated for a group of countries, comparison with which involves identifying the convergent nature of the structural dynamic trend;

$m$ is the time base (number of years) of the analysis of structural breaks.

Aggregated Converged Structural Shift Index (ACSSI) is a relative dimensionless value in the definition of which the geometric mean method was used:

$$
\operatorname{ACSSI}=\frac{\left(\prod_{i=1}^{n} \operatorname{KICSS}_{i}^{N}\right)^{1 / n}}{\left(\prod_{i=1}^{n} \operatorname{KICSS}_{i}^{S}\right)^{1 / n}}
$$

where: $n$ is the number of criteria $i$.

The use of the geometric mean method for aggregating the indices of structural shifts, calculated according to different criteria for certain types of structure over a significant period of time, is dictated by the application of this method in calculating various indices of economic development. Therefore, using the geometric mean, the Human Development Index (HDI) (until 2013 - the Human Development Index) is calculated, published in the framework of the United Nations Development Program [11].

\section{Results}

To calculate the object of comparison in the denominator of formula (3) - a group of countries, comparison with which presupposes the identification of the convergent nature of the structural and dynamic trend - we used the criterion index $\operatorname{KICSS}_{i}^{S}$, in the calculation of which, according to formula (2), the arithmetic mean of the indices of structural shifts $I_{i}^{S}$ was applied determined by formula (1) according to the structural dynamics of the blocs of the BRICS countries, the European Union (EU) and the United States, as well as additional data taken from a number of sources [12].

In turn, to calculate $\operatorname{KICSS}_{i}^{N}$ (the $i$-th criterion index of convergent structural shift), data on the structural dynamics of the Russian economy were taken. As a basis for calculating the indices of a convergent structural shift, 17 indicators were used, shown in Fig. 1.

The results of calculating the indices of structural changes $I_{i}^{N}$ (for the Russian economy) and $I_{i}^{S}$ (arithmetic mean for BRICS, EU and USA) for each of 17 criteria $(i)$ served as the basis for calculating the criterion indices $\operatorname{KICSS}_{i}^{N}$ (for Russia) and $\operatorname{KICSS}_{i}^{S}$ (arithmetic mean for BRICS, EU and US) for each of the 17 criteria ( $i)$, and are presented in Fig. 2. 
The values of the aggregated index of the convergent structural shift ACSSI more than 1 confirms its convergent nature; a value less than $1(0 ; 1)$ indicates the divergent nature of the shift.

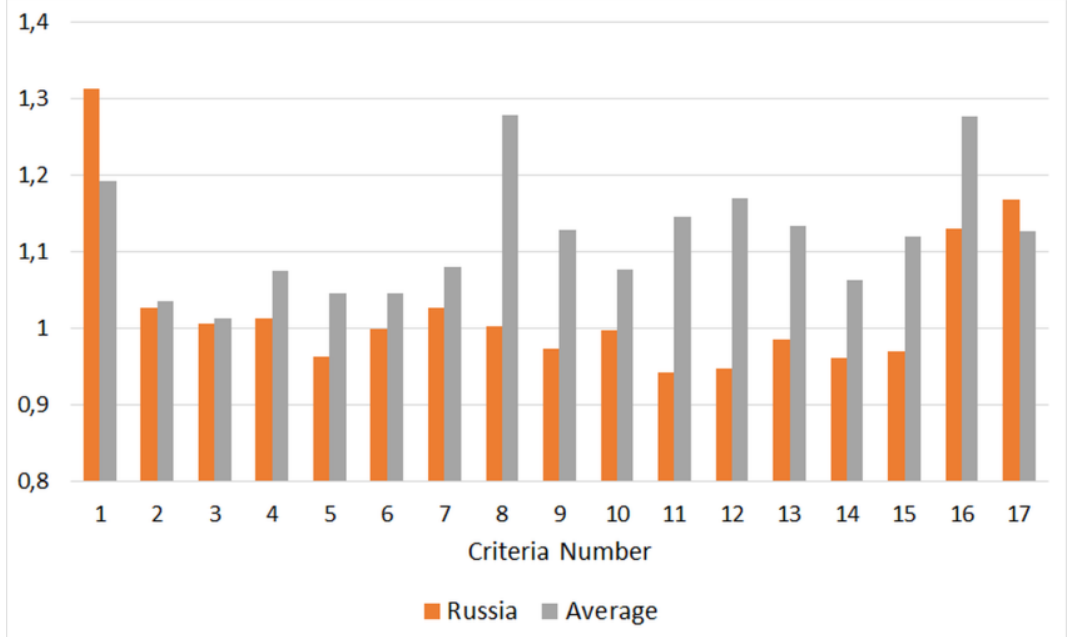

Fig. 2. Values of the criterion indices of the convergent structural shift for Russia and, on average, for a selected group of countries.

Arithmetically, the calculation of the aggregated convergent structural shift index is:

$$
A C S S I=\frac{\left(\prod_{i=1}^{n} \operatorname{KICSS}_{i}^{N}\right)^{1 / n}}{\left(\prod_{i=1}^{n} \operatorname{KICSS}_{i}^{S}\right)^{1 / n}}=\frac{1.022663}{1.122839}=0.91078
$$

The value of the aggregated index equal to 0.91078 (less than one) indicates a generally divergent trend of structural shifts that took place in the Russian economy in 1999-2000, with an increasing contradictory distance in terms of sustainable development and the nature of forces, their forming, both from the United States and the EU, and from the BRICS bloc as a whole. Overcoming such a divergent shift requires the formation of a convergent-oriented economic and environmental government policy.

\section{Conclusion}

The use of the method of quantitative analysis of the convergent structural shift, as applied to the transition to sustainable development, made it possible to draw a number of conclusions.

First, the transformational depression of the 1990s with the destruction of many structural elements of the Russian economy was replaced by a structural shift induced by exogenous factors, mainly by a significant improvement in the situation on the world market for raw materials and finance. However, endogenously determined structural proportions became opposite to global trends, which predetermined the lag in ecological, economic and technological development.

Secondly, since the beginning of the 2010s, a divergent structural shift has taken place in the Russian economy, in which not only trends in macroeconomic dynamics, but also changes in environmental indicators are opposite to shifts in developed countries. Endogenously induced, the divergent structural shift was a consequence of the separation of the structural 
policy of the state from the imperative of sustainable development, the transition to which requires a complex nature of structural changes.

Third, a divergent structural shift in the Russian economy is taking place against the background of a new stage in the sustainable development of the economies of countries, which is characterized by the modification of structural shifts due to the formation of new industries with low resource intensity and high productivity (alternative energy, production of electric vehicles, waste recycling, etc.), the development of inter-cluster investment and innovation interactions in the course of the expansion of convergent technologies.

\section{References}

1. E.A. Taran, V.A. Malanina, F. Casati, Economics and Innovation Management 4, 39-46 (2020)

2. E.A. Taran, Convergent structural shifts in the economy: thesis (SFU, Krasnoyarsk, 2020)

3. G.A. Barysheva, E.A. Frolova, V.A. Malanina, E.A.Taran, Active ageing index: A Russian study. In: Building Evidence for Active Ageing Policies: Active Ageing Index and its Potential (University of Southampton, Southampton, 2018)

4. V.V. Guzyr', Economics and Innovation Management, 4, 4-19 (2019)

5. M.A. Klimovich, M.A. Gasanov, Economics and Innovation Management, 2, 8-17 (2019)

6. S.M. Sukhorukova, A.M. Pogorely, A.V. Samorokov, Economics and Innovation Management, 2, 45-53 (2020)

7. S.M. Sukhorukova, A.M. Pogorely, A.V. Samorokov, Economics and Innovation Management, 1, 54-65 (2020)

8. M. Cehlar, Economics and Innovation Management, 3, 24-31 (2019)

9. S. Zhironkin, S. Demchenko, G. Kayachev, E. Taran, O. Zhironkina, E3S Web Conf. 105, 03008 (2019)

10. J. Ramirez, M. Baez, F. Casati, , L. Cernuzzi, B. Benatallah, E.A. Taran, V.A. Malanina, ACM International Conference on Web Search and Data Mining, WSDM 2021, 67-75 (2021)

11. UN Development programme. URL: https://www.undp.org/content/undp/en/home/

12. Dreaming With BRICs: The Path to 2050, Goldman Sachs Global Economics Paper, 99, 1-24 (2003) URL: https://www.goldmansachs.com/insights/archive/archive-pdfs/bricsdream.pdf 